\title{
Framework for Advancement of Women Working in Selected Regulatory Organizations in South Africa
}

\author{
Portia Mahwibi Tladi, Molefe Jonathan Maleka \\ Tshwane University of Technology, South Africa \\ TladiPM@tut.ac.za, MalekaM@tut.ac.za
}

\begin{abstract}
The purpose of this study was to develop a framework that would be used as a guideline for managers to create a conducive environment for women to advance into management positions in selected regulatory organizations operating in the maritime and aviation industries. The literature reviewed revealed that mentoring, employment equity legislation, and not confirming to stereotypes were some of the factors leading to women's advancement into management positions. Feminism and equity theory were used to give the study theoretical grounding. The research approach was qualitative, the population size was twenty $(\mathrm{N}=20)$ and the sample size was fifteen $(\mathrm{n}=15)$. The latter was attained after the saturation point had been reached. The research protocol was developed from the literature reviewed. Face-to-face interviews were conducted and qualitative content analysis was used to develop study themes manually. The major findings of the study were that these factors enhanced women's advancement into management positions: qualification and industry-related experience, fair recruitment and selection practices, proper handover, mastering worklife balance, and leadership and management development. It is envisaged that the results will empower managers and policy-makers dealing with employment equity, given the fact that women advancement into management positions is moving at a slow pace. In future a study can be conducted where a bigger sample size is used and the researchers could use the mixed-method approach. Furthermore, a follow-up study could be conducted using the same participants to establish whether they have advanced or not.
\end{abstract}

Keywords: Equity theory; feminism; management positions; regulatory organizations; women

\section{Introduction}

According to Kitada, Williams and Froholdt (2015), global research shows that female representation in management positions is not high. For example, Kitada et al. (2015) opine that $29 \%$ women in the Asian Pacific, 25\% in the European Union, 23\% in Latin America, and 21\% in the United States of America (USA) occupy management positions. Internationally, there are initiatives like Women's Empowerment Principles (see McWha-Hermann, Maynard \& Berry, 2016) and feminists groups who challenged the underrepresentation in top management positions (Gill, 2014). There are factors that prevent women from advancing into management positions. International literature revealed that not having relevant qualifications and experience (Alvesson \& Due Billing, 2009; Knight, 2016) and unfair and biased recruitment practices (Bratton, Callinan, Forshaw \& Sawchuk, 2007; O'Neil, Hopkins \& Sullivan, 2011) are some of the factors that hamper women's advancement into management positions. At the time of writing this article, there were frameworks of women advancement (see Chinyamuridi, 2016) however there was no framework with themes like leadership and management as factors leading to the advancement of women into management positions). Furthermore, there was no study that has been conducted before in the South African context, where data were collected from the "understudied" sample of women in management positions (Chinyamuridi, 2016: 9). Women are not advancing into management positions because they are accused of lacking masculine traits like being hard and autocratic (Griffin, Phillips \& Gully, 2014) and aggressive (Syed \& Murray, 2008). According to Kitada et al. (2015), women who work in male-dominated occupations tend to face challenges that differ from those who work in more gender-balanced and femaledominated occupations.

Problem statement: In the selected regulatory organizations in South Africa, where the present study was conducted, women in management position were expected to work long hours and they were invisible as female managers within the organization. Sometimes women had to be on standby (Kitada et al., 2015). The data showed that in 2013, in the industry where selected regulatory organizations operate, the gender representation was as follows: $80 \%$ males and 20\% women (Anno-Frempong, 2014). The data show that the vestiges of the past in South Africa created by draconian and brutal systems (i.e. colonialism and apartheid) of relegating women in low positions (Slutskaya, Simpson, Hughes, Simpson \& Uygur, 2016) and not being appointed in management positions still exist (Du Toit et al., 2015). Whereas research has been conducted 
internationally and in South Africa about women's under-representation in workplaces, thus far in South Africa, no study has been conducted to develop a framework of women's advancement into management positions in the selected regulatory organizations (i.e. maritime and aviation).This was the gap that this study wanted to address, with the following research objectives:

- to identify how qualifications and experience influence the advancement of women into management positions;

- to identify which human resource management (HRM) practices influence women in advancing into management positions;

- to identify labour relations (LR) practices that influence the advancement of women into management positions; and

- to identify how individual factors influence the advancement of women into management positions.

By addressing the above-mentioned objectives, the researchers envisaged that by using the framework that they had developed (refer to Figure 1):

- they would empower women managers working within the selected organizations with knowledge that would assist them to mitigate the factors that stymie women's advancement; and

- this would contribute to the theoretical literature on women's advancement.

In the sections below, the theoretical framework, the research methodology, the results and discussion are discussed.

\section{Theoretical framework}

Women's advancement can be defined as vertical and horizontal career progression influenced by factors such as education and experience, fair recruitment and selection policies, organizational culture, self-esteem, external factors (i.e. family support), and networking and/or attending informal meetings. This could be impeded by work-life balance, a lack of mentors, and stereotyping (Chinyamurindi, 2016). In order to give the study a theoretical grounding of women's advancement, feminist theory was used as theoretical framework. The primary goal of feminism is to champion women's rights against unequal treatment and organizational injustice (Gouws, 2012).Feminist theory was developed in the 1960s in the United States of America in order to advance the agenda of gender equality and women's advancement in organizations (Zippel, 2006). Some literature shows how in Africa, feminism gained prominence due to unfair labour practices of using women as cheap labour (Denzin \& Lincoln, 2011). In South Africa, not much has been written about feminism in industrial relations or HRM literature; hence, Nel, Kirsten, Swanepoel, Erasmus and Jordaan (2016) question its relevance as a theoretical framework.

A theoretical framework for women's advancement that has been cited in South African HRM literature is equity theory (Coetzee \& Schreuder, 2010). This theory states that employees, irrespective of whether they are men or women, should be treated equally (Robbins \& Judge, 2015). It can be argued that equity theory has some similarity with feminism theory, as both are also against unequal treatment of employees. Research in South Africa revealed that a lack of self-confidence (Booysen, 2007), as well as stereotypes (Choi \& Park, 2014) were some of the issues that stymie women's advancement into management positions. It had been found that the quality of work-life balance (i.e. the balance between work and family life), a lack of respect and being treated with dignity, 'old boys practice', and education and proper management training (LewisEnright, Crafford \& Crous, 2009) were some of the factors that worked against the advancement of women in management positions. Recent literature has shown that women who do not conform to gender stereotypes are likely to succeed as leaders (Cukier, Jackson, Elmi, Roach \& Cyr, 2015).

In South Africa, various legislation, policy, and gender commissions have been established to create opportunities for advancement of women into management positions. In terms of the latter, section 9(2) of the Constitution of South Africa and the Employment Equity Act (EEA), No. 55 of 1998, section 6(1), prohibit unequal treatment of employees based on their gender (Republic of South Africa, 1998). The EEA aims to ensure that the legacies of apartheid in the South African workplace are addressed and that equal opportunities and fair treatment are promoted through the elimination of unfair discrimination and the 
implementation of affirmative action measures to advance black people, women, and people with disabilities (Republic of South Africa, 1998). A Commission for Gender Equality was established in 1991and a gender policy framework was developed in 1996 (Gender Policy Framework, 2003). Despite these efforts, the Commission of Employment Equity (2016) shows that women are not equally represented in top management: $20 \%$ in private sector and $30.6 \%$ in the public sector.

Women do not progress because they do not have mentors (Bosch, 2011). It had been found that women who did not have mentors do not progress in their careers and they struggle to cope with work and family challenges and their well-being or health was affected in a negative way (Burke \& El-Kot, 2011:56). On the other hand, women who had mentors were empowered to cope with pressure and the masculine or maledominated organizational culture (Annis \& Gray, 2013). Based on the above discussion, it can be surmised that under-representativeness of women is a global phenomenon. It can be observed that in the selected regulatory organizations, there are human resources factors that influence the advancement of women in management positions. No theoretical framework could be found in South African literature that can be used by selected regulatory organizations to advance the careers of women in management positions. Therefore, the purpose of this study was to develop a framework that would assist managers to create a conducive environment for women to advance into management positions.

\section{Methodology}

In this section, the research design, population and sample, measuring instrument, research process, data analysis, trustworthiness, and ethical consideration are discussed.

Research design: In order to address the study objectives, a qualitative research approach was deemed appropriate. The research design was cross-sectional feminism research. The latter was selected because the researchers intended to solicit "experiences and viewpoints of women" (Kumar, 2014:160). Since the research approach was qualitative, the research epistemology was interpretivist because the researchers wanted to bring about a thorough understanding of women's experiences about what they perceived as factors leading to their advancement into management positions. The researchers also opted for a qualitative approach in order to solicit "multiple realities" (ontology) (Struwig \& Stead, 2013:15) of women.

Population and sample: The target population for this present study comprised twenty women managers at management level 1 to 4 (i.e. junior, middle, senior, and top management level) in two regulatory organizations in South Africa. A purposive sample was used to select participants, and the inclusion criteria to select participants were as follows:

- $\quad$ participants had to be women; and

- they had to be in management positions.

Out of the population of twenty women $(\mathrm{N}=20)$ managers, only fifteen $(\mathrm{n}=15)$ women managers were interviewed for this study. The rationale of interviewing fifteen women managers was that between interviewees twelve and fifteen, no new information emerged - meaning that a point of data saturation was reached (De Vos, Strydom, Fouché \& Delport, 2011).The sample size was within 5 to 25 range as suggested by Saunders, Lewis and Thornhill (2012). In Table 1, the biographical information of the participants is displayed.

Table1: Biographical information of participants

\begin{tabular}{llllll}
\hline Qualification & Occupational level & $\begin{array}{l}\text { Period } \\
\text { employment }\end{array}$ & of & $\begin{array}{l}\text { Field of specialization } \\
\text { (relevant/irrelevant) }\end{array}$ & $\begin{array}{l}\text { Gender } \\
\text { mentor }\end{array}$ \\
\hline Diploma & Middle manager & 5 years & Relevant & $\begin{array}{l}\text { Did not have } \\
\text { mentor }\end{array}$ \\
Diploma & Middle manager & 6 years & Relevant & $\begin{array}{l}\text { Did not have } \\
\text { mentor }\end{array}$ \\
Diploma & Middle manager & 13 years & Relevant & $\begin{array}{l}\text { Did not have } \\
\text { mentor }\end{array}$ \\
Diploma & Middle manager & 14 years & Relevant & Did not have
\end{tabular}




\begin{tabular}{|c|c|c|c|c|c|}
\hline Qualification & Occupational level & $\begin{array}{ll}\begin{array}{l}\text { Period } \\
\text { employment }\end{array} & \text { of } \\
\end{array}$ & $\begin{array}{l}\text { Field of specialization } \\
\text { (relevant/irrelevant) }\end{array}$ & $\begin{array}{l}\text { Gender } \\
\text { mentor }\end{array}$ & $\overline{\text { of }}$ \\
\hline & & & & mentor & \\
\hline Diploma & Senior manager & 16 years & Relevant & $\begin{array}{l}\text { Did not } \\
\text { mentor }\end{array}$ & have \\
\hline Diploma & Junior manager & 17 years & Relevant & $\begin{array}{l}\text { Did not } \\
\text { mentor }\end{array}$ & have \\
\hline Honours & Middle manager & 6 months & Relevant & Man & \\
\hline Honours & Junior manager & 5 years & Relevant & Woman & \\
\hline Honours & Junior manager & 8 years & Relevant & Man & \\
\hline Honours & Junior manager & 8 years & Relevant & Man & \\
\hline Master's & Executive manager & 2 months & Relevant & Male & \\
\hline Master's & Senior manager & 3 years & Relevant & $\begin{array}{l}\text { Did not } \\
\text { mentor }\end{array}$ & have \\
\hline Master's & Senior manger & 3 years & Relevant & $\begin{array}{l}\text { Did not } \\
\text { mentor }\end{array}$ & have \\
\hline Master's & Executive manager & 4 years & Relevant & $\begin{array}{l}\text { Did not } \\
\text { mentor }\end{array}$ & have \\
\hline Honours & Executive manager & 10 years & Relevant & $\begin{array}{l}\text { Did not } \\
\text { mentor }\end{array}$ & have \\
\hline
\end{tabular}

Source: Study results

From Table 1, it is clear that $27 \%$ of the participants were junior managers, $40 \%$ were middle managers, $20 \%$ were senior managers, and $13 \%$ were executive managers. The average working experience of the participants was 7.52 years.

Measuring instrument: An open-ended semi-structured interview protocol was designed and developed from the literature reviewed, and was aligned with the objectives of the study. The interview protocol consisted of two sections: Section A comprised questions relating to logistical information and the biographical details of participants. Section B covered broad areas of inquiry related to recruitment practices, mentoring, qualifications, and experience. The questions were structured in such a way that they addressed the research problem in question. Some of the research questions asked in Section B were as follows:

- How would you describe the recruitment process in the organization?

- How would you describe the recruitment practices in the organization?

- Which kind of strategies do you use to achieve work-life balance?

- How would you describe the career opportunities in the organization?

- What are the barriers for women's advancement in the organization?

Research process: Before the actual interviews, the researchers conducted a pilot study with two participants $(n=2)$ to ensure that the questions were clear and that the objectives of each section were understood. After the pilot study had been conducted, the researchers refined some of the questions (Saunders et al., 2012).Once the pilot had been conducted, the researchers agreed that one researcher would collect the data. Face-to-face interviews were conducted and these enabled the researcher to probe for further clarity when participants were not giving clear responses (Babbie \& Mouton, 2008).

Data analysis: In order to analyze data, the researchers followed five steps of analyzing data as suggested by Creswell (2014:197):

- $\quad$ organising and preparing data;

- $\quad$ reading through the data;

- coding the data;

- linking themes/descriptions; and

- interpreting the meaning of themes. 
Coding of data was conducted separately and the researchers met and agreed on themes. The researchers separately analyzed the data manually and met to agree on the codes - this is known as inter-coder agreement (Bless, Higson \& Sithole, 2013).

Trustworthiness: Below is a description of how the researchers achieved trustworthiness as suggested by Maree (2012:140-141):

- True value (credibility): member checking was not done as female managers could not be reached because of their busy schedule. Transcripts (i.e. primary data) were fused with secondary data during interpretation and analysis of the results to enhance triangulation. Prior to submission of the manuscript, the manuscript was given to a peer (i.e. an academic) to review. The feedback from the academic was important, and the changes were incorporated into the manuscript. In addition, the data were reported verbatim.

- Applicability (transferability): even though the researchers' aim was not to generalize the results to the population, the researchers were confident that the results of the study, which led to the framework of women's advancement, could be generalized other contexts. Yin (2015) argues that analytical generalisation is generalisation to theoretical proposition and not population.

- Consistency (dependability): the researchers explained the research procedure in detail, in anticipation that other researchers who follow the same steps would find similar results. To enhance the quality of the data collected, the data were recorded by audio recorder, which assisted the researchers in transcribing the data verbatim. Data were collected in the participants' offices where there were no disturbances.

- Neutrality (confirmability): transcripts were given to an independent academic, who did an 'audit trial' or verification that results were presented in a neutral manner. The researchers stored the results on compact disc, so that if other researchers want to view the transcripts, recordings, and other documents (i.e. interview protocol, ethical clearance letter, and informed consent), they can be made available.

Ethical considerations: No participant was coerced to participate and to enhance participants' anonymity, they were given pseudonyms during data collection. Prior to data collection, the interview protocol and informed consent form were submitted to the university's Central Ethics Committee for ethical approval, which was granted. Participants were also informed prior to the face-to-face interviews that they had the right to withdraw their participation during interviews and they had the right to not answer questions that made them uneasy.

\section{Results and Discussion}

The themes that emerged from the data were an entry to management positions, HRM and LR practices, and individual factors.

- Entry into management position: Qualification and experience: As can be observed from Table 1, the qualification of participants ranged from a national diploma to a master's degree. Furthermore, all participants had relevant qualifications related to the selected regulatory organizations. In terms of the relevance of the qualifications, during face-to-face interviews a participant said, "I've got an operational qualification that is the pilot licensing as well as the certificate of competence."

It also emerged from the data that the experience of participants ranged from two months to seventeen years. When interviewed, a participant made this assertion about working experience, "I think the qualification with the years of experience almost elevate you to an area of specialization so you are almost a specialist as expected in your area, that you would know the dynamics or you would have a better understanding of all the dynamics and new trends in the area." The findings of the present study are similar to what Alvesson and Due Billing (2009) and Knight (2016) found, namely that qualifications and relevant industry are key and rudimentary drivers to enter into management positions. 
HRM practices: Discussed in this section are recruitment and selection, mentorship, recognition and informal meeting, and leadership and management.

- Recruitment and selection: Participants mentioned that the recruitment and selection processes were transparent and fair. One participant said, "I would say that they are fair obviously we are looking at equity and we do look at gender so as far as that is concerned I would say that the recruitment process itself is very fair from HR [human resources] side."

On the other hand, men were preferred over women, and a participant mentioned, "It is about who you know mostly." This selection criterion perpetuated what is known as the "old boy network" (Wroblewski, 2014:296) and it stymies women's advancement into management positions.

- Mentorship: As can be observed from Table 1, most participants did not have mentors and there was a paucity of women mentors. Maleka's (2012) study revealed that mentorship was salient to the advancement of women managers. A participant responded that mentorship is salient, but mentioned that women were sometimes their own worst enemies: "I have mentored throughout my career several women. One of the women said I am shy."

A participant mentioned that mentorship played a critical role in her professional development and not advancement. She said,

"It [mentorship] plays a huge role but I wouldn't say in advancing me as a woman but advancing me in my professional development."

- Recognition and informal meeting: In order for women to advance, they have to work harder than men and without recognition. A participant mentioned, "As a woman have to work three times more than my male colleagues for me to be able to be recognised and for me to be able to achieve, not because you are a less achiever, sometimes people don't even take recognition of you unless you put the light on the mountain and shine."

This finding is similar to findings from a study by Evans (2011). Attending informal meetings is also essential for women's recognition and being part of decision-making in the maritime organization:

"I work with men that smoke... even though I don't smoke I have now learned to take my cup of tea and join them... a lot because those people, they are very informal yet they make constructive decisions."

Choi and Park (2014) also found that major decisions are taken in informal settings, and males endorsed those decisions in formal meetings.

- Leadership and management development: In order to equip women in decision-making, one participant mentioned that she was selected to attend a leadership and management development course: "You will find there was a programme of women in aviation and there were certain people that were selected and there was another one ... it was about women leadership."

Similarly, another participant said,

"There is this personal development programme that has been placed from our skills development unit with our HR. At the beginning of a financial year you draw up your business plan for the year and in that you also have to identify personal development programmes that you think that can help you to advance in your line of duties or functions."

Robbins, Odendaal and Roodt (2007) argue that leadership and management development capacitate both male and female managers to advance because they empower them to learn skills that would make them competent. In terms of HRM practices, the data disconfirmed what is written in the literature, namely that mentorship affects women's advancement. Instead, it emerged from the data that mentorship assisted with professional development. It also emerged that women's lack of confidence caused them not to advance and demoralised the mentor. Interestingly, five out fifteen participants were advancing without having mentors. 
LR practices: Discussed in this section are employment equity and discrimination.

- Employment equity: Section 6 of the Employment Equity Act (EEA) No. 55 of 1998 and section 9 of the Constitution of the Republic of South Africa guide HR departments to appoint and promote women into management positions. In terms of the former, HR must submit an employment equity plan to the Department of Labour to show it is compliant with race and gender equity. In terms of the latter, a participant said, "On the EXCO level, you still get a lot of males; I think we have two or three women if I am not mistaken. In this of 21 years of democracy you will think organizations will have a balance..."

This response reinforces what was discussed in the introduction section, namely that women are not equally represented in South African and global organizations (Du Toit et al., 2015; Slutskaya et al., 2016). A participant said the following about handover,

"Starting of it was quit hectic for me because what we decided is that the previous gentleman (he is still around) will do a handover over a period of three months."

However, Sanderson and Whitehead (2016) found that males were barriers to women's advancement.

- Discrimination: not only are women under-represented; in order to advance, they have to deal with and overcome discriminatory practices. The data revealed that there were no advancement policies; hence, few women were advancing into executive positions: "There are no policies. Even if you go check on our executive level there is only two women and the second women was just hired three months ago, while the other time there was only one woman executive so there is really no programme or policies that is helping with the advancement of women."

It also emerged that the discriminatory and stringent criteria stymies women to advance in other careers, "I am not going to be a senior manager in flight operations because I need 7500 flying hours... Any women today ... whether they are white or black, not anyone of them can actually meet those requirements that they have set."

This finding is not consistent with section 6 of EEA, No. 55 of 1998, and section 2(2), schedule 7 of the Labour Relations Act, No. 66 of 1997, which stipulate that there must be equal opportunity, fair treatment, no discriminatory practices, and advancement of women (Horwitz \& Jain, 2011). It also emerged that the criteria "are unrealistic "and only suited "very old white males that have been in the industry for a very long time."

Individual factors: Discussed in this section are work-life balance, masculinity or assertiveness, selfconfidence, and career advancement.

- Work-life balance: Women use different strategies in order to balance between work and family responsibilities. Some participants responded by saying, "I work very late hours. Also when it is time to write tests, I sleep late, get up at 02:00, sleep an hour and I still need to be [at work];" and

"When the kids go to bed at about 20:00, then I continue to study, then I will sleep for two hours, then I will wake up at 01:00 and I study until I get to work. My husband wasn't very happy about that."

Zinn (2016) cautions that women in management have to be flexible and able to balance between their family responsibilities and at the same time they have to be able to rest so that they perform optimally in the workplace. A participant eloquently said, "There is no formula. "This finding is in line with the narrative that says that there is no "one size-fits all approach" (Urban, 2010:1) in achieving work-life balance.

- Masculinity or assertiveness: women who were in management positions were undermined in management rendezvous and some instances males "will look at you as [a woman] to take notes."

The same participant mentioned that it frustrated her and she had to change her personality and be masculine or assertive, 
"So you have to become a different person in order to survive in this environment. You have to harden yourself."

When lamenting about the masculine culture dominant in the organization, she poignantly said,

"I think the biggest problem we have is the fact that there is still that very traditional view of a woman being at home raising her children."

- Self-confidence and career advancement: women who are confident look for opportunities to advance themselves. It was found that in both organizations there were career advancement opportunities, and a confident participant said the following, "If they advertise a position that will interest me obviously I will put my CV [curriculum vitae] forward and make myself available for that."

Another participant was confident that her exposure would lead to her career advancement,

"I think I am exposed in a way with different stakeholders and different environments (nationally, internationally and regionally). So the career opportunities for me should not be a problem. It depends on how I carry myself in those forums."

Research revealed that employees, irrespective of their gender, who were confident, were more likely to advance in their careers than those who were not confident (Potgieter, 2012). Based on the data of the study, Figure 1 presents a framework for women'sadvancement.

\section{Figure 1: Framework for advancement of women into management positions}

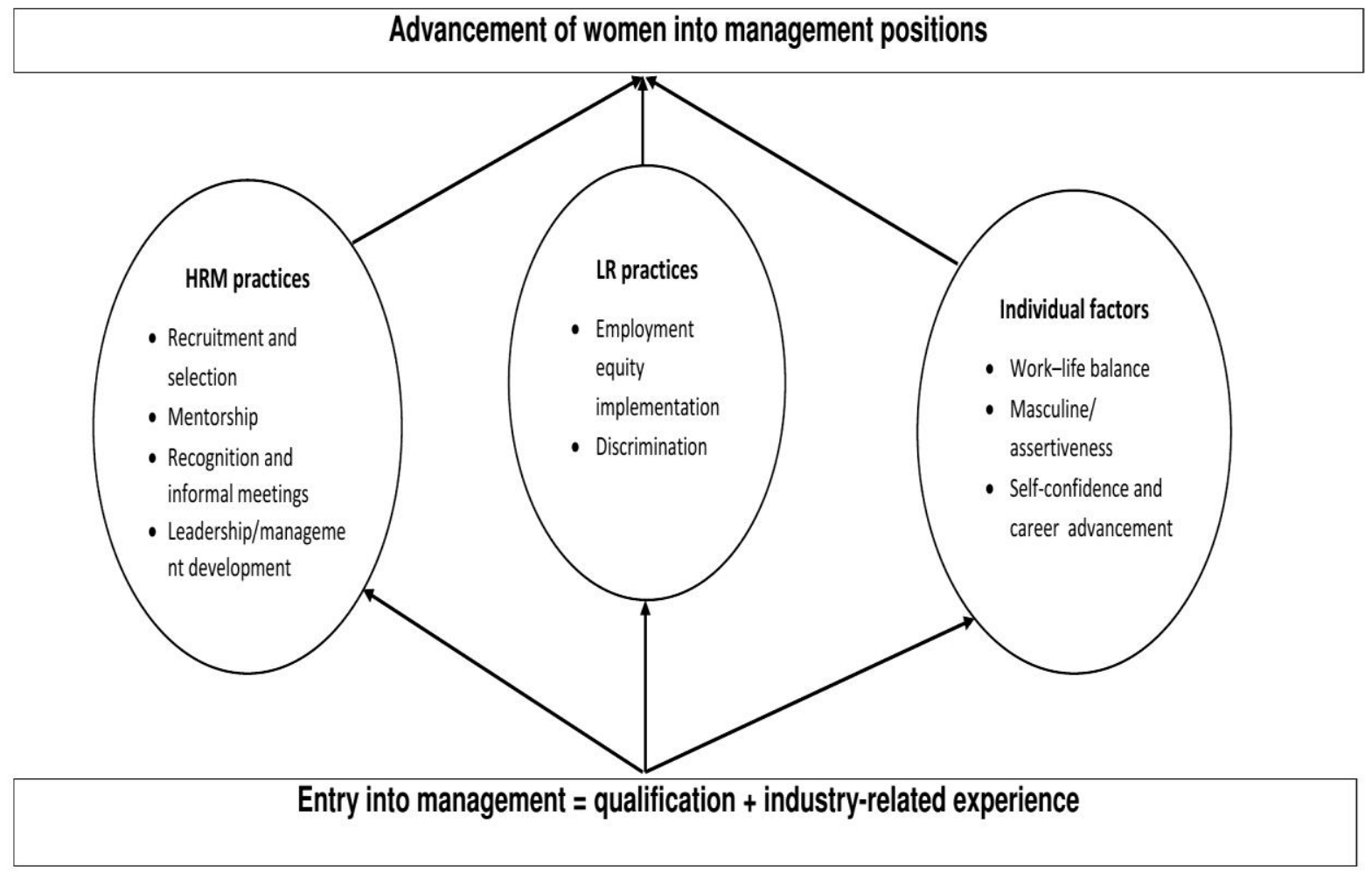

Source: Study results

\section{Conclusion and Recommendations}

Based on the study findings, it can be concluded that even though there were few women managers in the selected organizations, the ones who were in management were in a better position to advance to senior management positions. The data revealed that there were fair HR recruitment and selection practices, and 
there were leadership and management development opportunities. In some instances, a male was willing to do proper handover, women mastered balancing work and life, and they were assertive and there were career opportunities for advancement. The present study used a small population size because there were few women in management positions in the selected regulatory organizations. The findings can therefore not be generalized to the population in other industries; however, they can be applied to similar situations or beyond the actual study (Yin, 2015). A further limitation was that, due to a lack of trust, the participants were not free to express their experiences and perceptions of factors thwarting the progression of women. In future, a study can be conducted where a bigger sample size is used and the researchers could use the mixedmethod approach. Furthermore, a follow-up study could be conducted using the same participants to establish whether they have advanced or not. In terms of the managers of selected organizations, the following recommendations are made in order to advance more women:

- mechanisms should be made available by organizations to give women more exposure so that they can meet the long hours of being trained as pilots;

- organizations should appoint more mentors to assist women with professional and career development opportunities;

- organizations should build facilities (i.e. crèches) within their premises for children so that women should not have to worry about the children at home whilst they are working long hours; and

- flexible working hours should be introduced to HRM policies to retain skilled and educated women in management.

Furthermore, it is recommended that managers in selected organizations should use the framework suggested in Figure to attract and retain women in management positions.

Policy implication: The data revealed that there was a disjuncture in terms of EAA policy and appointment requirements that excluded women in certain professions. This finding shows that policy makers have the mammoth task of ensuring that these demographics (i.e. women) are not ostracized in the regulatory workplaces, by employers who create barriers that make them not to be appointed and selected into management positions. Since it emerged from the data that there no policies to women appointment and selection into management positions, policy makers have the responsibility to enforce that such a policy is developed and implemented. The policy makers should also deploy officials to closely monitor the implementation of such a policy. Lastly, policy-makers should create avenues or opportunities for women to be capacitated so that they can meet this criterion as an entry into senior management: "I am not going to be a senior manager in flight operations because I need 7500 flying hours."

\section{References}

Alvesson, M. \& Due Billing, Y. (2009). Understanding gender and organizations. Los Angeles, CA: Sage.

Annis, B. \& Gray, J. (2013). Work with me: How gender intelligence can help to succeed at work and life. New York, NY: Palgrave MacMillan.

Anno-Frempong, M. (2014). Transport education and training authority women in transport summit presentation. [Online] Available at: http://www.transport.gov.za/Portals/0/Projects/sanwit\% 202015/teta\%20presentation\%20for\%20women\%20summit\%202015.pdf.Accessed 25/06/2016.

Babbie, E. \& Mouton, J. (2008). The practice of social research ( $\left.8^{\text {th }} \mathrm{ed}\right)$, Cape Town: Oxford University Press Southern Africa.

Bless, C., Higson-Smith, C. \& Sithole, S. L. (2013). Fundamentals of social research methods: An African perspective ( $6^{\text {the }}$ ), Claremont: Juta.

Booysen, L. (2007). Barriers to employment equity implementation and retention of blacks in management in South Africa. South African Journal of Labour Relations, 31(1), 47-71.

Bosch, A. (2011). The South African Board for People Practices (SABPP) Women's Report 2011. Parktown: SABPP.

Bratton, J., Callinan, M., Forshaw, C. \& Sawchuk, P. (2007). Work and organizational behaviour: Understanding the workplace. New York, NY: Palgrave MacMillan.

Burke, R. J. \& El-Kot, G. (2011). Gender similarities in work and well-being outcomes among managers and professionals in Egypt. International Journal of Gender and Entrepreneurship, 3(1), 56-74. 
Chinyamurindi, W. T. (2016). A narrative investigation into the meaning and experience of career success: Perspective from women participants. South African Journal of Human Resource Management, 14(1), $1-11$.

Choi, S. \& Park, C. (2014). Glass ceiling in Korean Civil Service: Analyzing barriers to women's career advancement in the Korean government. Public Personnel Management, 43(1), 118-139.

Coetzee, M. \& Schreuder, D. (2010). Personnel psychology: An applied perspective. Cape Town: Oxford University Press.

Commission of Employment Equity. (2016). Employment Equity Report. [Online] Available at: http://www.labour.gov.za/DOL/downloads/documents/annual-reports/employment-equity/20152016/16th\%20CEE\%20Report.pdf. Accessed 24/06/2016.

Creswell, J. W. (2014). Research design (4thed), Los Angeles, CA: Sage.

Cukier, W., Jackson, S., Elmi, M. A., Roach, E. \& Cyr, D. (2016). Representing women? Leadership roles and women in Canadian broadcast news. Gender in Management: An International Journal, 31(5), 374395.

Denzin, N. K. \& Lincoln, Y. S. (2011). The Sage handbook of qualitative research (4thed), Los Angeles, CA: Sage.

De Vos, A. S., Strydom, H., Fouché, C. B. \& Delport, C. S. L. (2011). Research at grass roots. Pretoria: Van Schaik.

Du Toit, D., Godfrey, S., Cooper, C., Giles, G., Cohen, T., Conradie, B. \& Steenkamp, A. (2015). Labour relations law: A comprehensive guide. Durban: LexisNexis.

Evans, D. (2011). Room at the top: Advancement and equity for women in the business world. National Civil Review, 100(2), 62-64.

Gill, R. (2014). Unspeakable inequalities: Post-feminism, entrepreneurial subjectivity, and the repudiation of sexism. Social Politics, 21(4), 509-528.

Gouws, A. (2012). Reflection on being a feminist academic/academic feminist in South Africa: Equality, diversity and inclusion. An International Journal, 31(5), 526-541.

Griffin, R. W., Phillips, J. M. \& Gully, S. M. (2014). Organizational behaviour: Managing people and organizations (11 thed), Boston, MA: Cengage Learning.

Horwitz, F. M. \& Jain, C. (2011). An assessment of employment equity and broad based economic empowerment developments in South Africa. Equality, Diversity and Inclusion, 30(4), 297-317.

Kitada, M., Williams, E. \& Froholdt, L. L. (2015). Maritime women: Global leadership. Berlin/Heidelberg, DE: Springer.

Knight, M. (2016). Racing, classing and gendering racialized women's participation in entrepreneurship. Gender, Work \&Organization, 23(3), 310-327.

Kumar, R. (2014). Research methodology: A step-by-step guide for beginners ( $4^{\text {th }}$ ed), Los Angeles, CA: Sage.

Lewis-Enright, K., Crafford, A. \& Crous, F. (2009). Towards a workplace conducive to the career advancement of women. South African Journal of Industrial Psychology/Suid-Afrikaanse Tydskrifvir Bedryfsielkunde, 35(1), 136-144.

Maleka, M. J. (2012). An in-depth investigation of the factors contributing to employee dissatisfaction at the business application solution centre (BASC), ESKOM (DLitt et Phil-thesis). University of South Africa, Pretoria.

Maree, K. (2012). Complete your thesis or dissertation successfully: Practical guidelines. Claremont: Juta.

Mcwha-Hermann, I., Maynard, D. C. \& Berry, M. O. (2016). Humanitarian work psychology and the global development agenda: Case studies and interventions. London, UK: Routledge Taylor \& Francis Group.

Nel, P. S., Kirsten, M., Swanepoel, B. J., Erasmus, B. J. \& Jordaan, B. (2016). South African employment relations: Theory and practice. Pretoria: Van Schaik.

O’Neil, D. A., Hopkins, M. M. \& Sullivan, S. E. (2011). Do women's networks help advance women's careers? Career Development International, 16(7), 733-754.

Potgieter, I. (2012). The attributes between self-esteem and employability of attributes of postgraduate business management students. South African Journal of Human Resource Management, 10(2), 1-15.

Republic of South Africa. (1996). The Constitution of the Republic of South Africa, No. 108 promulgated on 18 December 1996 and commenced in February 1997. [Online] Available at: http://www.gov.za/structure/constitution.htm.Accessed 20/06/2016.

Republic of South Africa. (2003). National gender policy framework: women's empowerment and gender equality, national gender policy framework. [Online] Available at: http://www.info.gov.za/otherdocs/2000.gender.pdf.Accessed 20/06/2016.

Robbins, S. P. \& Judge, T. A. (2015). Organizational behaviour (16 $\left.{ }^{\text {th }} \mathrm{ed}\right)$, Boston, MA: Pearson Education. 
Robbins, S. P., Odendaal, A. \& Roodt, G. (2007). Organizational behaviour: Global and Southern African perspectives ( $7^{\text {thed }}$ ), Cape Town: Pearson Education.

Sanderson, R. E. \& Whitehead, S. (2016). The gendered international school: Barriers to women managers' progression. Education and Training, 58(3), 328-338.

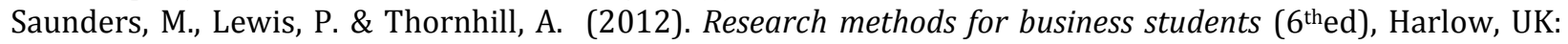
Pearson Education.

Slutskaya, N., Simpson, R., Hughes, J., Simpson, A. \& Uygur, S. (2016). Masculinity and class in the context of dirty work. Gender, Work and Organization, 23(2), 165-182.

Struwig, F. W. \& Stead, G. B. (2013). Research: Planning, designing and reporting. Cape Town: Pearson Education.

Syed, J. \& Murray, P. A. (2008). A cultural feminist approach towards managing diversity in top management teams. Equal Opportunities International, 27(5), 413-432.

Urban, B. (2010). A gender preference on career preference and entrepreneurship self-efficacy. South African Journal of Human Resource Management, 8(1), 1-8.

Wroblewski, A. (2014). Gender bias in appointment procedures for full professors: challenges to changing traditional and seemingly gender neutral practices. Gender transformation in the academy, 19, 291313.

Yin, R. B. (2015). Case study research. Los Angeles, CA: Sage.

Zinn, S. (2016). Swimming upstream: A story of grit and determination to succeed. Randburg: KR Publishing.

Zippel, K. S. (2006). The politics of sexual harassment: A comparative study of the United States, the European Union and Germany. London, UK Cambridge University Press. 